\title{
Novos materiais têxteis - Um estudo sobre moda e sustentabilidade
}

\author{
New textile materials - A study on fashion and sustainability
}

MARQUES, Adrienne Fioravante; Graduanda; Centro Universitário Franciscano. adrienne.fioravante@gmail.com

BOMBONATTI, Bruno Londero; Graduando; Centro Universitário Franciscano. brunolonderobombonatti@gmail.com

GRIGOLO, Graziela da Silva; Graduanda; Centro Universitário Franciscano. grazielagrigolosm@gmail.com

ROSA, Jéssica Seixas da; Graduanda; Centro Universitário Franciscano. jessicaseixasdarosa@gmail.com

LUZ, Felipe Ferreira; Professor; Centro Universitário Franciscano. felipe.ferreira.luz2gmail.com

\section{Resumo}

A atenção gerada em torno da moda sustentável tem se intensificado a cada dia. Estudos e pesquisas discutem a temática em seus diversos segmentos e tentam encontrar novas possibilidades para uma produção têxtil ecologicamente correta e ética. Dentre as alternativas está à utilização de materiais têxteis sustentáveis, capazes de gerar um menor impacto ao meio ambiente e à sociedade. Com base nisso, o presente artigo tem como objetivo abordar os conceitos de sustentabilidade na moda, em função dos materiais empregados. Além disso mostrar o potencial de aplicações de novos materiais têxteis bem como materiais inusitados através de uma pesquisa de opinião de consumidores.

Palavras Chave: novos materiais; moda; sustentabilidade. 


\section{Abstract}

The attention generated around sustainable fashion has intensified every day. Studies and research discuss the theme in its various segments and try to find new possibilities for an ecologically correct and ethical textile production. Among the alternatives is the use of sustainable textile materials, capable of generating a lesser impact on the environment and society. Based on this, this article aims to approach the concepts of sustainability in fashion, depending on the materials used. In addition, show the potential of applications of new textile materials as well as unusual materials through a consumer opinion survey.

Keywords: new materials; fashion; sustainability.

\section{Introdução}

Nos últimos anos, estudos e pesquisas têm se intensificado no campo da moda sustentável, também chamada de moda ecologicamente correta, verde ou ética, promovendo discussões e reflexões sobre os mais diversos segmentos do assunto. Envolvendo todo o ciclo de produção e consumo do vestuário, desde as fibras, o processo de desenvolvimento de tecidos, o uso da peça pelos consumidores e o descarte final. Os materiais utilizados ao longo deste processo de produção influenciam diretamente os sistemas ecológicos e sociais, ou seja, o meio ambiente e sociedade, causando impactos que em sua grande maioria são negativos. A geração de resíduos tóxicos pelas indústrias têxteis é um dos exemplos de ação, que atinge de maneira negativa diretamente os sistemas, favorecendo uma produção em massa de materiais que não possuem potencial para biodegradação.

Conforme estudo realizado pela Associação Brasileira da Indústria Têxtil e de Confecção (ABIT), o Brasil está em quinto lugar como maior produtor têxtil do mundo. Este dado enfatiza o potencial setorial no país, significando uma produção em larga escala que gera impactos diretos e indiretos em questões socioambientais. Assim, se faz necessário procurar alternativas sustentáveis ao longo do processo, que gerem o menor percentual de impacto negativo ao ecossistema, tendo atenção no beneficiamento das fibras, no modo como são desenvolvidos os tecidos, as estampas, entre outras etapas da produção têxtil.

Dentre todo o processo, os materiais empregados são cruciais na produção, eles representam o ponto de partida do processo e quando relacionado com a sustentabilidade representam a fonte de geração de novos tecidos ecologicamente corretos. Para Fletcher e Grose (2011) até o momento, a exploração de materiais tem sido o ponto inicial para a maior parte da inovação sustentável na moda (p.12), e se pararmos para refletir sobre o pensamento das autoras, a situação atual da moda sustentável continua concentrada nos materiais, evidenciando a potencialidade têxtil encontrada em novos materiais, fortalecendo a ideia de que o foco nesse segmento é o caminho para uma produção mais consciente e responsável, valorizando matérias-primas provenientes da natureza, capazes de renovação.

O campo da moda já está em processo de mudança para uma produção mais sustentável. As emissões de carbono na última década e seus impactos negativos nas condições climáticas e o uso intensivo de pesticidas em plantações, por exemplo, acionaram uma preocupação nas 
indústrias têxteis, que gerou a procura de soluções ecologicamente corretas para as futuras produções (FLETCHER;GROSE, 2011).

Portanto, neste artigo tem-se como objetivo apresentar a sustentabilidade atrelada ao campo da moda, em função de novos materiais empregados, que surgem a cada dia com base em pesquisas e estudos científicos, através de um levantamento de pesquisas realizadas com diversas fontes, como livros, revistas, publicações acadêmicas e pesquisa via internet. E como parte experimental, aplicou-se um questionário online, com a intenção de apontar o potencial comercial de aplicação de novos materiais têxteis, bem como materiais inusitados, através de uma pesquisa de opinião de consumidores.

\section{Materiais ecologicamente corretos e a biodegradação}

Ao longo dos anos, percebe-se uma maior atenção às matérias-primas utilizadas nas produções das indústrias têxteis. Os motivos são variados, como o excesso de resíduos descartados ao longo das confecções, os estoques que acabam se tornando lixo e as propriedades tóxicas que compõem os materiais. Essa atenção está interligada ao princípio de sustentabilidade e o destino que os resíduos gerados têm após seu período de uso, pelo consumidor final. Segundo Muchinski et al. (2014) às grandes empresas necessitam desenvolver produtos ecologicamente corretos e que sejam benéficos ao meio ambiente e também à sociedade, cultivando o propósito de conscientização ambiental, que impacta diretamente a cadeia produtiva e os consumidores.

Ainda segundo o autor, as fibras têxteis sustentáveis estão entre as matérias-primas que menos agridem o meio ambiente, reforçando a ideia de que é necessário investir em materiais ecologicamente corretos, como por exemplo, nas fibras de bambu, milho e soja, que possuem potencial sustentável e de biodegradação.

O processo de biodegradação das fibras acontece de forma específica para cada tipo de material, no qual "são decompostas em substâncias mais simples por microrganismo, luz, ar ou água, em processo que deve ser atóxico e que ocorre ao longo de período relativamente curto" (FLETCHER e GROSE, 2010). Como mencionado anteriormente, cada fibra reage de uma forma no processo de decomposição e algumas nem têm potencial para serem biodegradáveis. Por exemplo, nas fibras naturais, a decomposição ocorre de forma automática, nas fibras sintéticas, feitas a partir de um material derivado do carbono, não ocorre a decomposição. Já nas fibras derivadas de plantas e animais a decomposição é aceita e ocorre em partículas simples.

É importante destacar que na maioria dos casos, essas fibras de origens distintas não são usadas de maneira isolada na produção têxtil. Pelo contrário, as roupas são produzidas a partir de uma mescla de fibras, gerando uma composição de propriedades que inibem a biodegradação e consequentemente produzem resíduos, que se acumulam no meio ambiente. E para além da mescla de fibras, outro fator não favorece a decomposição. O uso de aviamentos e etiquetas compostas de materiais distintos causa uma desaceleração no processo de biodegradação completa. Para Fletcher e Grose (2011), esse processo só acontece quando é projetado e planejado com antecedência, evitando a mescla de fibras e o uso de linhas e aviamentos não biodegradáveis.

No entanto, sabemos que a aplicação de fibras biodegradáveis na indústria têxtil não é um processo simples e rápido, por isso é importante ter noção de alguns obstáculos: 
Quadro 1: Obstáculos para a biodegradação

- A criação de peças de vestuário totalmente biodegradáveis em que todas as fibras e partes componentes decompõem-se de forma completa e segura;

- O desenvolvimento de infraestrutura adequada para coletar e processar fibras degradáveis por compostagem;

- A disponibilização de informações mais precisas e a identificação das fibras biodegradáveis, especificando métodos de compostagem e diferenças com relação a sintéticos não degradáveis e degradáveis derivados do petróleo.

Fonte: Fletcher e Grose (2011)

\section{Compostagem: Uma alternativa para a biodegradação}

Quando falamos em ciclo de vida de uma peça de roupa, imaginamos o seu processo de desenvolvimento até o uso pelo consumidor e acabamos esquecendo de uma etapa importante que é o seu destino final. Dentre as alternativas está a compostagem, método pouco divulgado na área têxtil mas que pode ser uma saída sustentável para os resíduos têxteis que não são mais utilizados.

O método da compostagem é mais comum em propriedades agrícolas, utilizado para potencializar o solo, mas também está sendo adotado em áreas urbanas, com objetivo de reduzir os resíduos domésticos, que normalmente são transportados para aterros sanitários.

Portanto, a compostagem é um processo que acontece em diferentes fases, e seu período é relativo, dependendo do tipo de material que está sendo decomposto. São técnicas que estimulam a decomposição de materiais orgânicos. Basicamente, para acontecer o processo é necessário ter compostos químicos e condições ideais de temperatura, umidade, disponibilidade de $\mathrm{CO} 2$ e $\mathrm{O} 2$. Como resultado final do processo, os resíduos são transformados em compostos orgânicos, que proporcionam benefícios para o solo.

Em 2010, a empresa de vestuário suíça Freitag criou uma linha de roupas 100\% biodegradáveis, com a mistura de cânhamo, linho e modal. A proposta da Freitag é a produção de peças de longa duração e que ao chegarem ao seu estágio final de uso possam ser descartadas em um processo de compostagem, decompondo-se sem agredir o meio ambiente.

\section{Materiais têxteis inusitados}

Materiais inusitados são aqueles que formam um conjunto de materiais, comuns ou não, mas que são incomuns em aplicações têxteis ou de moda. Esse conjunto de materiais quando empregados na moda atendem os quesitos técnicos para uma aplicação têxtil, como resistência, proteção, alongamento e caimento. Logo, sua aplicação é incomum, tornando-se assim, um material inusitado.

Atualmente, empresas brasileiras e do exterior estão desenvolvendo seus produtos com materiais inusitados, incentivando uma produção sustentável e consciente. 


\section{Tecido feito de teia de aranha}

Novo no mercado, o tecido produzido com teia de aranha apresenta em suas características roupas resistentes e transgênicas. Pela primeira vez, este tipo de material é usado em uma roupa que, além de funcional, também pode ter boa aparência. O processo de tecelagem desse fio acontece quando o bicho da seda recebe o gene da aranha, com isso, através de suas fiandeiras os mesmos produzem o tecido de tal forma que ocorra a mistura de proteínas da aranha e do bicho da seda. O material híbrido resultante é composto de menos de $1 \%$ de proteína de aranha, mas é 53\% mais resistente que a seda normal. Sabe-se também que o material produzido pelas aranhas para traçar suas teias é cinco vezes mais forte do que um fio de aço do mesmo tamanho e que se ele fosse da espessura de um lápis poderia até parar um Boeing. Por conta disso, é considerado o uso da seda da aranha para tudo, de fio cirúrgico a colete à prova de balas.

Figura 1 - Tecido dourado feito a partir da fibra da teia de aranha

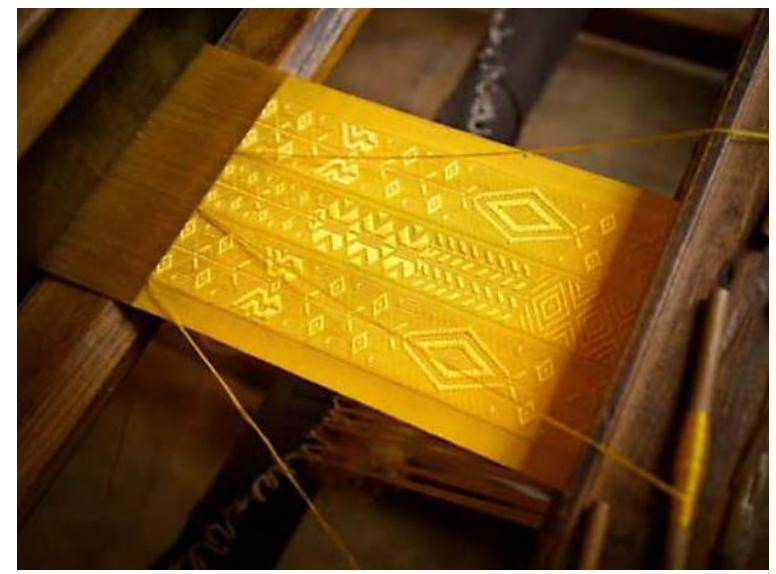

Fonte: BBC Brasil (2012)

\section{Tecido feito de cogumelos, que pode substituir a camurça}

A empresa italiana Grado Zero Espacce, desenvolveu um tecido resistente no mercado feito à base de cogumelos. O Muskin é um material extraído da parte superior dos cogumelos e processado de forma semelhante ao couro, e sem produtos químicos que dão uma textura semelhante à camurça. Uma das características do material é que ele tem grande capacidade de absorver umidade e depois liberá-la, sendo impermeável naturalmente e 100\% natural. Dentre as vantagens do material está a ausência de produtos químicos, tornando o tecido não tóxico e ideal para fabricação de peças que têm contato direto com a pele. Outra vantagem é que o Muskin não promove a proliferação de bactérias, sendo capaz de ser usado também em palmilhas, sapatos ou pulseiras de relógio, absorvendo a umidade e liberando-a.

$\mathrm{O}$ tecido pode ser usado para produções de bolsas, chapéus, até mesmo calçados, entre outros produtos. 
Figura 2 - Tecido produzido com cogumelo

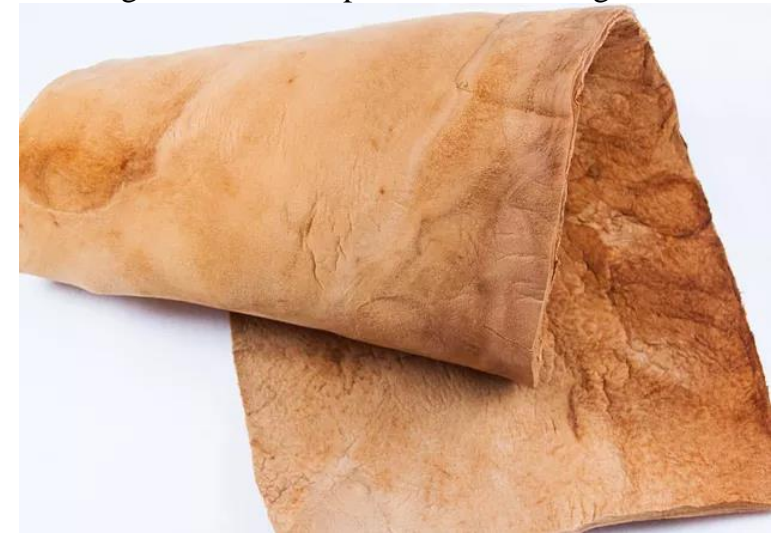

Fonte: Site Lorsa Modas (2017)

\section{Tecido feito com a fibra do abacaxi}

O Piñatex pode ser considerado o resumo da sustentabilidade, por que produz um tecido através das folhas do abacaxi, resultando em tecidos semelhantes ao couro animal. Além de poupar animais, as fibras de celulose extraídas das folhas são consideradas subproduto da agricultura e sem o uso, estragariam ou seriam queimadas. Esse tecido sustentável foi criado pela designer Carmen Hijosa e é produzido nas Filipinas. Para as fibras ficarem semelhantes ao couro elas são separadas e feltradas em um pano sem trançados que pode ser usado em roupas, sapatos e móveis. O Piñatex é flexível e leve, além de poder levar costuras e ter padrões impressos em sua superfície. O material não é completamente biodegradável, porque possui uma camada protetora para garantir sua durabilidade.

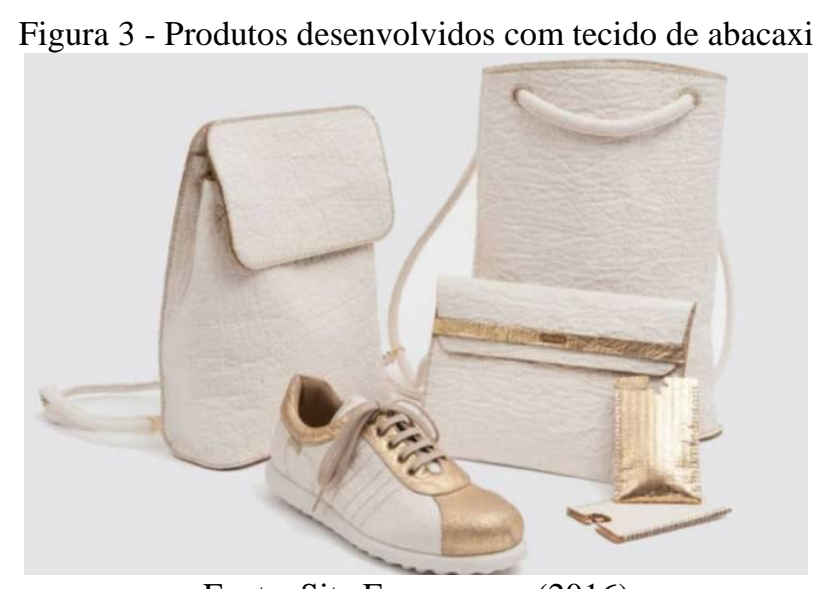

Fonte: Site Exame.com (2016)

Outro exemplo de utilização do Piñatex vem da Finlândia, através da marca Taikka, na qual são desenvolvidas bolsas sustentáveis com esse material inusitado. São produtos com toque suave e estão disponíveis para compra em modelos e cores variadas. 


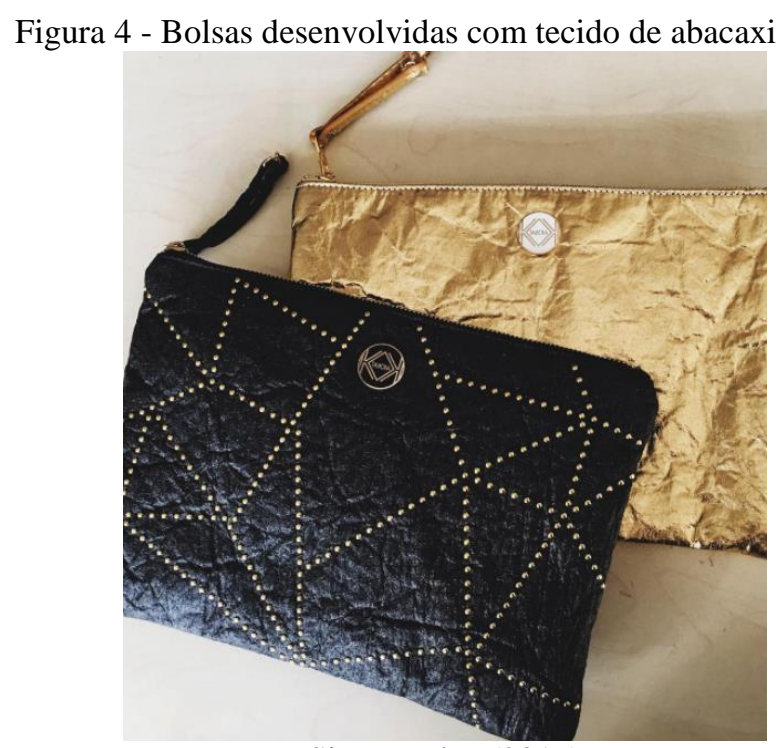

Fonte: Site Estadão (2017)

\section{Tecido feito com óleo e fibra da uva}

$\mathrm{O}$ arquiteto italiano Gianpero Tessitore, da empresa Vegea recentemente criou um novo tecido a partir de óleos e fibras da uva semelhante ao couro, apenas feito com resíduos da produção de vinho, como sementes, cascas e talos da uva. O novo material desenvolvido foi denominado Wineleather, ele tem um processo de transformação dos resíduos, pois o material é similar ao couro e não utiliza água, ácidos ou metais pesados. "A ideia veio em 2014, quando me dei conta de que as indústrias de moda, móveis e couro não tinham uma alternativa verde e cruelty-free para o tradicional couro animal ou sintético", disse Gianpiero ao site Unfiltered.

Depois de realizada a extração do suco da fruta, o próximo passo é submeter a um processo de desidratação e separação, além de passar por processos mecânicos e posteriormente a mistura da substância que fornecerá um novo tecido com aspectos de textura, estética e funções semelhantes ao couro.

Atualmente são feitos diversos testes para viabilizar a aplicação do Wineleather em embalagens, carros, transportes e mobílias. 
Figura 5 - Tecido semelhante ao couro

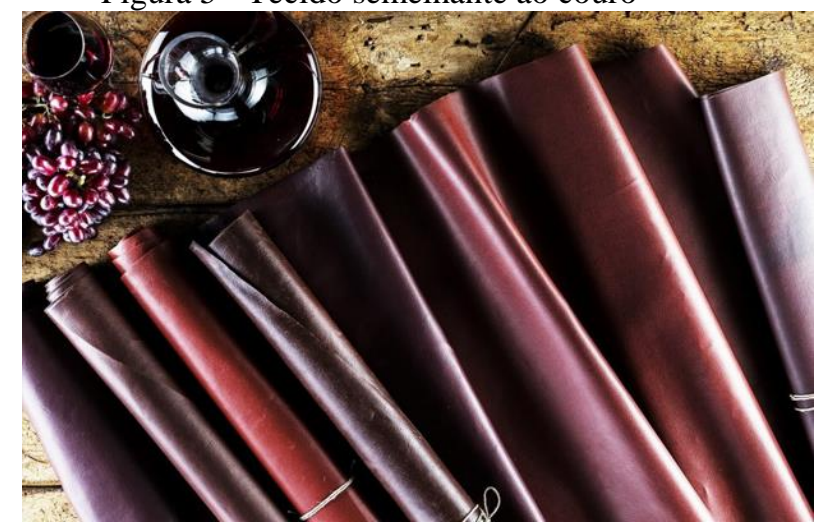

Fonte: Site Follow Tremendous Content At (2017)

Na tabela abaixo identificou-se alguns dos novos materiais têxteis e suas características, ainda pouco conhecidos pelo mercado da moda:

Tabela 1 - Materiais Inusitados

\begin{tabular}{|c|c|c|c|}
\hline Nome & Origem & $\begin{array}{c}\text { Simbologia ABNT/ } \\
\text { DIN }\end{array}$ & Características \\
\hline Bambu & Vegetal & - & $\begin{array}{c}\text { Extremamente macio, com toque } \\
\text { de seda } \\
\text { Tecido confortável }\end{array}$ \\
\hline Borra de café & Vegetal & - & $\begin{array}{c}\text { Tecido fresco } \\
\text { Secagem rápida } \\
\text { Absorve odores }\end{array}$ \\
\hline Bananeira & Vegetal & - & $\begin{array}{c}\text { Textura macia } \\
\text { Versátil }\end{array}$ \\
\hline Cupro & Artificial & CC & $\begin{array}{c}\text { Confortável } \\
\text { Transpiração } \\
\text { Maciez } \\
\text { Absorção } \\
\text { Brilho }\end{array}$ \\
\hline $\begin{array}{c}\text { Cogumelo } \\
\text { (Muskin) }\end{array}$ & Vegetal & & Anti-odores \\
& & & Anti-UV \\
\hline $\begin{array}{c}\text { Abacaxi } \\
\text { (Piñatex) }\end{array}$ & Vegetal & & $\begin{array}{c}\text { Tecido versátil } \\
\text { Respirável } \\
\text { Forte } \\
\text { Flexível } \\
\text { Leve }\end{array}$ \\
\hline & & & $\begin{array}{c}\text { Resistente } \\
\text { absorver humidade }\end{array}$ \\
\hline
\end{tabular}

6o GAMPI Plural, 2017, Joinville, SC. 


\section{GAMPI}

\begin{tabular}{|c|c|c|c|}
\hline Caseína & Animal & - & Semelhante ao nylon e seda \\
\hline Soja & Artificial & - & Toque e brilho próximos da seda \\
\hline Cânhamo & Vegetal & CH & $\begin{array}{c}\text { Boa resistência e durabilidade } \\
\text { Capacidade de absorção } \\
\text { Resistente ao bolor }\end{array}$ \\
\hline Milho & Artificial & - & $\begin{array}{c}\text { Textura macia } \\
\text { Confortável } \\
\text { Resistente à transpiração }\end{array}$ \\
\hline $\begin{array}{c}\text { Casca de caranguejo } \\
\text { (Crabyon) }\end{array}$ & Animal & - & $\begin{array}{c}\text { Toque macio } \\
\text { Versátil } \\
\text { Fácil tingimento }\end{array}$ \\
\hline $\begin{array}{c}\text { Aranha } \\
\text { Uva } \\
\text { (Wineleather) }\end{array}$ & Animal & - & Resistência e durabilidade \\
\hline
\end{tabular}

Fonte: Autores (2017)

\section{Novos materiais têxteis: pesquisa de opinião}

Nota-se que grandes marcas do vestuário já estão experimentando novos materiais têxteis, em suas produções. Isso mostra o potencial que esses materiais inusitados possuem e agregam para a área da moda, resultando em produções diferenciadas e aliadas a preocupação ambiental. Com base nesta questão, elaborou-se um questionário online, através da plataforma google forms, no qual o objetivo compreende analisar a aplicabilidade mercadológica dos novos materiais têxteis, mais especificamente, da fibra da folha de abacaxi e da teia de aranha.

Ao todo, 27 pessoas responderam o questionário, em sua maioria do público feminino, com idade entre 15 e 30 anos.

A figura 6 apresenta as respostas, com relação a conhecerem ou não o conceito de moda sustentável. Com base nas respostas, percebe-se que a maioria dos entrevistados $(48,1 \%)$ conhece o conceito, enquanto o restante já ouviu falar $(29,6 \%)$, mas não tem um aprofundamento no assunto ou não conhece $(22,2 \%)$. A figura 7 mostra a opinião dos entrevistados, em relação a comprar ou não uma peça de roupa produzida com teia de aranha. Como resultado, obteve-se uma porcentagem alta afirmando comprar $(88,9 \%)$, enquanto uma minoria optou em não comprar $(11,1 \%)$. Ainda com relação ao tecido de teia de aranha, foi perguntado por que o entrevistado compraria ou não a peça, e dentre as respostas foram selecionadas as principais: (i) Compraria por curiosidade, para conhecer, (ii) Por ser uma alternativa inovadora, (iii) Por que achei estranho, (iv) Se o custo for menor, compraria. 
Figura 6 - Você conhece o conceito de moda sustentável.

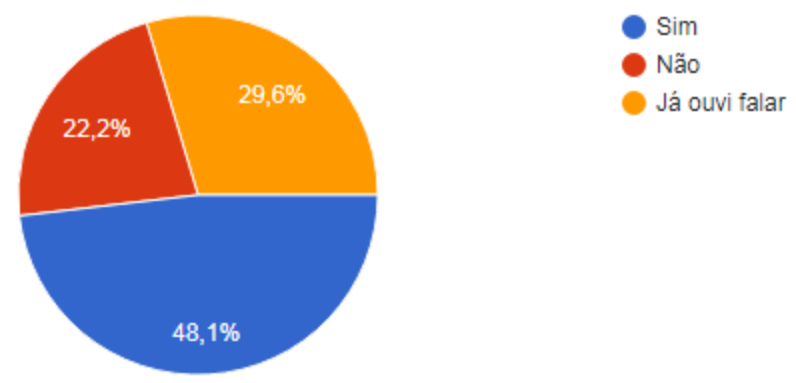

Fonte: Dos autores (2017)

Figura 7 - Você compraria uma peça de roupa produzida com teia de aranha.

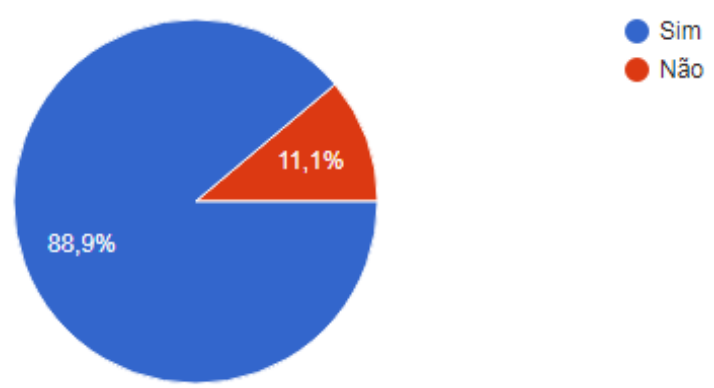

Fonte: Dos autores (2017)

Já na figura 8, apresentam-se as respostas dos entrevistados sobre comprar ou não uma peça de roupa confeccionada com fibras da folha do abacaxi. Os resultados mostram que a maioria dos entrevistados $(92,6 \%)$ compraria a peça sustentável, enquanto que uma minoria $(7,4 \%)$ não estaria disposta a comprar. Ainda com relação à peça de fibra de abacaxi, o entrevistado foi questionado, tendo que responder por que compraria ou não a peça, e dentre as respostas foram selecionadas as principais: (i) Não vejo motivo para não usar, além de se tratar de uma ideia sustentável, é um retrocesso ainda utilizar couro animal como matériaprima, (ii) Compraria para experimentar e ver se realmente vale a pena investir neste tipo de tecnologia, e incentivar o consumo de produtos com um cuidado maior com o meio ambiente, (iii) Compraria pelo aspecto de ser parecido com o couro.

$\mathrm{Na}$ figura 9, os entrevistados responderam se estariam dispostos a pagar um valor elevado, por uma peça de roupa feita de materiais sustentáveis. Dentre as opções de resposta, percebe-se que as opções talvez e sim foram as mais contempladas, onde $44,4 \%$ talvez e $40,7 \%$ sim, estivessem dispostas a apagar um valor maior, enquanto 14,8\% disseram não estar dispostas a investir um valor maior em peças com materiais sustentáveis. 


\section{GAMPI
plural ${ }^{47}$}

Figura 8 - Você compraria uma peça de roupa produzida com fibra de abracaxi.

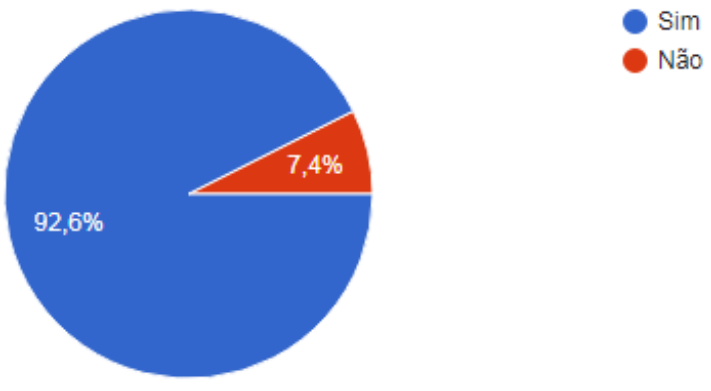

Fonte: Dos autores (2017)

Figura 9 - Você estaria disposto a pagar um valor maior por uma peça feita de materiais sustentáveis.

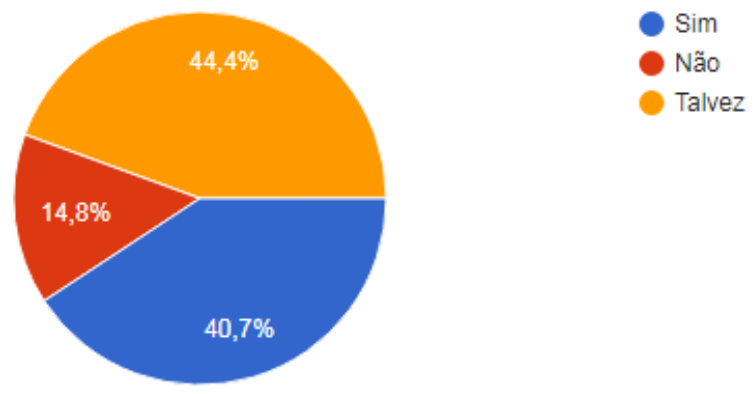

Fonte: Dos autores (2017)

Em síntese, ao analisar as respostas obtidas com o questionário constatou-se que a maioria dos entrevistados conhece o conceito de moda sustentável, contribuindo com a proposta central do artigo. Além disso, observou-se que houve uma elevada aceitação dos entrevistados com relação ás inovações têxteis, especificamente, referindo-se as fibras de abacaxi e teia de aranha, mostrando que esses materiais inusitados tem potencialidade para aplicação no mercado da moda sustentável.

\section{Considerações finais}

Ao longo deste trabalho evidenciou-se que o tema possui um vasto campo ainda a ser explorado, devido aos inúmeros novos materiais que surgem a cada dia, através de pesquisas e estudos, empenhados em uma moda sustentável. Além disso, percebeu-se uma carência de bibliografias que abordem a moda e sua relação com novos materiais, para além dos materiais considerados tradicionais. No entanto, com base no material encontrado sobre o tema, já foi possível discutir as vantagens e aplicações que os materiais possuem se utilizados na produção têxtil, destacando um processo inovador, com potencial elevado e ecologicamente correto. Outro aspecto relevante é a constatação de que é possível extrair matérias primas dos 
mais diversos e inusitados materiais, que até então, em um primeiro momento não são pensados como potencializadores para o desenvolvimento de novos materiais têxteis sustentáveis, tornando-os assim materiais que podem representar uma mudança significativa na indústria têxtil, assim abrindo caminhos para uma nova forma de produzir tecidos ecologicamente corretos.

\section{Referências}

ANICET, Anne; RUTHSCHILLING, Evelise Anicet. Relações entre moda e sustentabilidade. In: Colóquio de Moda, 9, 2013.

GWILT, Alison. Producing sustainable fashion: The points for Positive Intervention by the Fashion Designer em GWILT, A.; RISSANEN T, T. Shaping Sustainable Fashion: Changing the way we make and use clothes. $1^{\text {a }}$ ed. London: Earthscan, 2011.

FlETCHER, Kate GRASE, Lynda; (Org.). Moda \& Sustentabilidade, Design Para Mudança. São Paulo: Editora Senac, 2011.

MUCHINSKI, César Henrique; SENA, Taisa Vieira. Fibras têxteis sustentáveis: algodão colorido e orgânico, fibras de bambu, soja e milho. Iniciação - Revista de Iniciação Científica, Tecnológica e Artista, $\mathrm{n}^{\circ}$ 1, junho 2015. Disponível em: <http://www1.sp.senac.br/hotsites/blogs/revistainiciacao/wpcontent/uploads/2015/06/83_artigo_Iniciacao_ed-vol-5_n1_2015.pdf > - Acesso em 06 de maio de 2017. 